\title{
Mitochondrial Ataxias
}

\author{
Josef Finsterer
}

\begin{abstract}
Mitochondrial disorders (MIDs) are an increasingly recognized condition. The second most frequently affected organ in MIDs is the central nervous system. One of the most prevalent clinical CNS manifestations of MIDs is ataxia. Ataxia may be even the dominant manifestation of a MID. This is why certain MIDs should be included in the classification of heredoataxias or at least considered as differentials of classical heredoataxias. MIDs due to mutations of the mitochondrial DNA, which develop ataxia include the MERRF, NARP, MILS, or KSS syndrome. More rarely, ataxia may be a feature of MELAS, LHON, PS, MIDD, or MSL. MIDs due to mutations of the nuclear DNA, which develop ataxia include LS, SANDO, SCAE, AHS, XSLA/A, IOSCA, MIRAS, MEMSA, or LBSL syndrome. More rarely ataxia can be found in AD-CPEO, AR-CPEO, MNGIE, DIDMOAD, CoQdeficiency, ADOAD, DCMA, or PDC-deficiency. MIDs most frequently associated with ataxia are the non-syndromic MIDs. Syndromic and non-syndromic MIDs with ataxia should be delineated from classical heredoataxias to initiate appropriate symptomatic or supportive treatment.
\end{abstract}

RÉSUMÉ: Ataxies mitochondriales. Les maladies mitochondriales (MM) sont des maladies de plus en plus connues. Le second organe le plus fréquemment touché dans les MM est le système nerveux central. L'ataxie est l'une des manifestations cliniques les plus fréquentes de l'atteinte du SNC dans les MM. L'ataxie peut même être la manifestation dominante d'une MM. Ceci explique pourquoi certaines MM devraient être incluses dans la classification des hérédoataxies ou à tout le moins considérées dans le diagnostic différentiel des hérédoataxies classiques. Les MM dues à des mutations de l'ADN mitochondrial qui entraînent de l'ataxie comprennent les syndromes MERRF, NARP, MILS et KSS. Les MM suivantes provoquent plus rarement de l'ataxie : MELAS, LHON, PS, MIDD et MSL. Les MM dues à des mutations de l'ADN nucléaire qui provoquent de l'ataxie sont : LS, SANDO, SCAE, AHS, XSLA/A, IOSCA, MIRAS, MEMSA et le syndrome LBSL. On rencontre plus rarement de l'ataxie dans : AD-CPEO, AR-CPEO, MNGIE, DIDMOAD, le déficit en CoQ, ADOAD, DCMA et le déficit en PDC. Les MM plus souvent associées à l'ataxie sont les MM non syndromiques. On devrait distinguer les MM syndromiques et non syndromiques avec ataxie des hérédoataxies classiques afin d'instituer un traitement symptomatique ou de soutien approprié.

Can. J. Neurol. Sci. 2009; 36: 543-553

Hereditary mitochondrial disorders (MIDs) affect the respiratory chain (RC) or oxidative phosphorylation (OXPHOS) in the majority of the cases. Mitochondrial disorders are due to mutations in either mitochondrial DNA (mtDNA) or nuclear DNA (nDNA) located genes, why transmission of these mutations follows an autosomal dominant (AD), autosomal recessive (AR), X-chromosomal recessive (XL), or maternal trait. Phenotypically, MIDs present in the majority of cases as multi-system disease with onset between birth and senescence, although single-organ affection may dominate at onset of the disease $^{1,2}$. MIDs predominantly manifest in tissues/organs with high-energy requirements ${ }^{3}$, such as the peripheral nervous system (PNS), central nervous system (CNS), eyes, inner ears, endocrine glands, heart, intestines, kidneys, or bone marrow ${ }^{4}$. Combinations of organ affection constitute mitochondrial syndromes (syndromic MIDs), for which well known acronyms have been adopted (Table 1$)^{4}$. In the majority of cases, however, the phenotype does not comply with one of these syndromes (non-syndromic MIDs). The CNS is the second most frequently affected organ in MIDs and ataxia may be a dominant CNS manifestation of MIDs. If ataxia predominates the presentation of MIDs (ataxia neuropathy spectrum) ${ }^{5}$, it may be easily mixed up with classical heredoataxias.

Classical heredoataxias represent a heterogeneous group of neurological disorders, clinically characterized by a cerebellar syndrome with imbalance, progressive gait and limb un-

From the Krankenanstalt Rudolfstiftung, Vienna, Austria, Europe.

Received March 13, 2009. Final Revisions Submitted May 20, 2009.

Correspondence to: J. Finsterer, Postfach 20, 1180 Vienna, Austria, Europe. 
Table 1: Syndromic mitochondrial disorders

\begin{tabular}{|c|c|}
\hline ADOAD & $\begin{array}{l}\text { Autosomal dominant optic atrophy and } \\
\text { deafness }\end{array}$ \\
\hline AHS & Alpers Huttenlocher syndrome \\
\hline ANS & Ataxia neuropathy spectrum disorders \\
\hline $\mathrm{ARCO}$ & $\begin{array}{l}\text { Autosomal recessive cardiomyopathy and } \\
\text { ophthalmoplegia }\end{array}$ \\
\hline CMT2A & Charcot-Marie-Tooth \\
\hline CPEO & Chronic external ophthalmoplegia \\
\hline DCMA & Dilated cardiomyopathy with ataxia \\
\hline DDS (MTS) & $\begin{array}{l}\text { Deafness dystonia syndrome (Mohr } \\
\text { Tranebjaerg syndrome) }\end{array}$ \\
\hline DIDMOAD (WFS) & $\begin{array}{l}\text { Diabetes insipidus, diabetes mellitus, optic } \\
\text { atrophy, and deafness syndrome (Wolfram } \\
\text { syndrome) }\end{array}$ \\
\hline FA & Friedreich ataxia \\
\hline GRACILE & $\begin{array}{l}\text { Growth retardation, Fanconi type } \\
\text { aminoaciduria, cholestasis, iron overload } \\
\text { (liver hemosiderosis, hyperferritinemia, } \\
\text { hypotransferrinemia, increased transferrin } \\
\text { iron saturation, and free plasma iron), } \\
\text { profound lactic acidosis, and early death }\end{array}$ \\
\hline IOSCA & Infantile onset spinocerebellar ataxia \\
\hline KSS & Kearns Sayre syndrome \\
\hline LHON & Leber's hereditary optic neuropathy \\
\hline LS & Leigh syndrome \\
\hline MCHS & Myo-cerebro-hepato spectrum disorders \\
\hline MDS & Mitochondrial depletion syndrome \\
\hline MELAS & $\begin{array}{l}\text { Mitochondrial encephalomyopathy, } \\
\text { lactacidosis, stroke-like episodes }\end{array}$ \\
\hline MEMSA & $\begin{array}{l}\text { Myoclonus epilepsy myopathy and sensory } \\
\text { ataxia }\end{array}$ \\
\hline MERRF & Myoclonic epilepsy and ragged red fibers \\
\hline MIDD & Mitochondrial diabetes and deafness \\
\hline MILS & Maternally inherited Leigh syndrome \\
\hline MIRAS & Mitochondrial recessive ataxia syndrome \\
\hline MLASA & $\begin{array}{l}\text { Autosomal recessive sideroblastic anemia with } \\
\text { mitochondrial myopathy and lactic acidosis }\end{array}$ \\
\hline MNGIE & $\begin{array}{l}\text { Mitochondrial neuro-gastro-intestinal } \\
\text { encephalomyopathy }\end{array}$ \\
\hline MSL & Multiple systemic lipomatosis \\
\hline NARP & $\begin{array}{l}\text { Neurogenic muscle weakness, ataxia, and } \\
\text { retinitis pigmentosa }\end{array}$ \\
\hline OPA & Optic atrophy \\
\hline PDC & Pyruvate dehydrogenase complex deficiency \\
\hline PS & Pearson syndrome \\
\hline SANDO & $\begin{array}{l}\text { Sensory ataxic neuropathy, dysarthria, } \\
\text { ophthalmoplegia }\end{array}$ \\
\hline SCAE & $\begin{array}{l}\text { Juvenile-onset spino-cerebellar ataxia and } \\
\text { epilepsy }\end{array}$ \\
\hline XLSA & $\mathrm{X}$-linked sideroblastic anemia \\
\hline $\mathrm{XLSA} / \mathrm{A}$ & $\mathrm{X}$-linked sideroblastic anemia with ataxia \\
\hline
\end{tabular}

coordination, dysarthria, or disturbed eye movements. Heredoataxias are most frequently classified according to the mode of inheritance (AD, AR, or XL) ${ }^{6}$. Mitochondrial disorders with ataxia as part of the phenotype may also be inherited via an $\mathrm{AD}, \mathrm{AR}, \mathrm{XL}$ or maternal trait but have gained little attention so far. With the rapidly increasing prevalence of MIDs, however, an increasing number of MIDs with ataxia are reported. This review aims to give an overview of recent advances and current knowledge about the frequency, clinical presentation, genetic background, management, and prognosis of hereditary MIDs associated with sensory, spinal, or cerebellar ataxia.

\section{Methods}

The source of the disorders listed below was a MEDLINE search covering the years 1966 to February 2009 and using the key words: ataxia, sensory ataxia, cerebellar ataxia, mitochondrial respiratory chain, mitochondrial disorder, and all acronyms of syndromic MIDs listed in Table 1.

\section{Definitions}

Ataxia was defined as uncoordination and unsteadiness due to cerebral failure to regulate the body's posture or regulate strength and direction of limb movements ${ }^{7}$. Ataxia is usually a manifestation of a cerebral disorder, particularly of the cerebellum (cerebellar ataxia) or due to a spinal or peripheral lesion (sensory ataxia). Cerebellar and sensory ataxia manifest as uncoordinated movements, or unsteady stance and gait. Additional manifestations of cerebellar ataxia may be nystagmus or dysarthria, which often distinguish central and peripheral ataxia. Sensory ataxia can be compensated by opening the eyes, whereas cerebellar ataxia persists with open or closed eyes ${ }^{7}$.

\section{Frequency of mitochondrial ataxias}

No convenient figures are reported about the prevalence of ataxia in MIDs. Only figures about the general prevalence of MIDs are available, estimating that 9/100,000 individuals have a manifest MID $^{8}$. Additionally, 16.5/100,000 children and adults are at risk for the development of a MID ${ }^{8}$. The prevalence of the MERRF mutation $8344 \mathrm{~A}>\mathrm{G}$ in North East England is $0.4 / 100000^{8}$. The most common POLG1 mutation, $467 \mathrm{~A}>\mathrm{T}$, has been reported to occur in $0.6 \%$ of the Belgian population ${ }^{9}$.

\section{Classification of mitochondrial disorders}

Most frequently, MIDs are classified according to the type of the mutated gene. A first group of MIDs is due to mutations in mtDNA located genes (Table 2). Mitochondrial disorders due to mtDNA mutations are further classified as MIDs due to point mutations, which are maternally inherited and homoplasmic or exclusively heteroplasmic (Table 2), or as single deletions or duplications, which are sporadic and heteroplasmic. Point mutations may either affect tRNA or rRNA genes (MELAS, MERRF) or genes encoding for RC subunits (LHON, NARP, MILS). Single deletions or duplications are responsible for $\mathrm{CPEO}$, PS, or $\mathrm{KSS}^{2}$. The second group of MIDs is due to mutations in nDNA located genes, which are divided into genes encoding for RC subunits (LS, non-syndromic MID), for assembly factors of RC subunits (LS, GRACILE syndrome), for proteins involved in intergenomic signaling, causing breakage syndromes (AD-CPEO, AR-CPEO, SANDO, SCAE, AHS, MNGIE), depletion syndromes (non-syndromic MID, AHS), or translation defects (MLASA), for proteins involved in the CoQ metabolism (LS, non-syndromic MID), for proteins involved in the mitochondrial transport machinery (X-linked DDS (MTS) 
Table 2: Classification of mitochondrial disorders according to the genetic background

\begin{tabular}{|c|c|c|c|c|}
\hline MID & MI & Mutated gene(s) & mtDNA & nDNA \\
\hline \multicolumn{5}{|l|}{ mtDNA genes } \\
\hline \multicolumn{5}{|c|}{ 1. Point mutations in genes encoding for tRNAs or rRNAs (homoplasmic or heteroplasmic) } \\
\hline MELAS & mat & tRNAs, rRNAs & PM (homplasmic or heteroplasmic) & $\mathrm{n}$ \\
\hline MERRF & mat & tRNAs, rRNAs & PM (homplasmic or heteroplasmic) & $\mathrm{n}$ \\
\hline MSL & mat & tRNAs & PM (homplasmic or heteroplasmic) & $\mathrm{n}$ \\
\hline MIDD & mat & tRNAs & PM (homplasmic or heteroplasmic) & $\mathrm{n}$ \\
\hline \multicolumn{5}{|c|}{ 2. Point mutations in genes encoding for RC subunits (homoplasmic and heteroplasmic) } \\
\hline LHON & mat & $\mathrm{RC}$ subunits & $\mathrm{PM}$ & $\mathrm{n}$ \\
\hline NARP & mat & $\mathrm{RC}$ subunits & PM & $\mathrm{n}$ \\
\hline MILS & mat & RC subunits & PM & $\mathrm{n}$ \\
\hline \multicolumn{5}{|c|}{ 3. Single deletions/duplications (sporadic, heteroplasmic) } \\
\hline PS & mat & multiple RC subunits, RNAs & Single deletion/duplication & $\mathrm{n}$ \\
\hline KSS & mat & multiple RC subunits, RNAs & Single deletion/duplication & $\mathrm{n}$ \\
\hline
\end{tabular}

nDNA genes

\begin{tabular}{|c|c|c|c|c|}
\hline \multicolumn{5}{|l|}{$\mathrm{RC}$ subunits } \\
\hline LS & $\mathrm{AD}, \mathrm{AR}$ & $\mathrm{RC}$ subunits, assembly factors & $\mathrm{n}$ & PM, deletion \\
\hline \multicolumn{5}{|c|}{ Intergenomic signaling } \\
\hline AD-CPEO & $\mathrm{AD}$ & POLG1, ANT1, twinkle & mtDNA breakage syndrome & PM \\
\hline AR-CPEO & AR & $P O L G 1$ & mtDNA breakage syndrome & PM \\
\hline SANDO & $\mathrm{AR}$ & POLG1 & mtDNA breakage syndrome & PM \\
\hline SCAE & $\mathrm{AR}$ & $16 q 21-q 23$ & mtDNA breakage syndrome & Uk \\
\hline AHS & $\mathrm{AR}$ & POLG1 & mtDNA depletion syndrome & $\mathrm{PM}$ \\
\hline MNGIE & AR & Thymidine phsophorylase & mtDNA breakage syndrome & $\mathrm{PM}$ \\
\hline IOSCA & $\mathrm{AR}$ & C10orf2 (twinkle) & mtDNA depletion syndrome & PM \\
\hline MIRAS & $\mathrm{AD}$ & POLG1 & multiple mtDNA deletions & PM \\
\hline MEMSA & uk & POLG1 & $\mathrm{n}$ & PM \\
\hline ADOAD & $\mathrm{AD}$ & OPA1 & multiple mtDNA deletions & $\mathrm{PM}$ \\
\hline \multicolumn{5}{|l|}{ CoQ production } \\
\hline LS & AR & CoQ pathway & Uk & Uk \\
\hline \multicolumn{5}{|c|}{ Mitochondrial transport machinery } \\
\hline DDS (MTS) & XL & $D D S$ & $\mathrm{n}$ & Deletion \\
\hline XLSA & $\mathrm{XL}$ & $A B C 7$ & $\mathrm{n}$ & PM \\
\hline \multicolumn{5}{|c|}{ Mitochondrial maintenance } \\
\hline CMT2A & $\mathrm{AD}, \mathrm{AR}$ & Mitofusin-2 & $\mathrm{n}$ & PM \\
\hline \multicolumn{5}{|l|}{ Other } \\
\hline LBSL & $\mathrm{AR}$ & DARS2 & $\mathrm{n}$ & $\mathrm{PM}$ \\
\hline DIDMOAD & AR & $W F S 1, W F S 2$ & multiple mtDNA deletions & PM \\
\hline FA & $\mathrm{AR}$ & Frataxin & $\mathrm{n}$ & GAA-expansion \\
\hline DCMA & Uk & DNAJC19 & $\mathrm{n}$ & $\mathrm{PM}$ \\
\hline
\end{tabular}

MI: mode of inheritence, mat: maternal inheritance, PM: point mutations, del: deletion, dupl: duplication, uk: unknown, n: normal

XLSA), or for proteins involved in mitochondrial maintenance (CMT2A (mitofusin-2) $)^{10}$.

\section{Diagnosis of mitochondrial disorders}

The diagnosis of a MID is based on clinical, chemical, electrophysiological, histological, biochemical, and genetic investigations. Phenotypic features suggesting a MID include abnormalities of the PNS (myopathy including ocular muscles, neuropathy, neuronopathy), CNS (epilepsy, migraine, stroke-like episodes, ischemic stroke, ataxia, Parkinsonism, dystonia, optic atrophy, cognitive decline, psychiatric abnormalities, coma), endocrine glands (short stature, pituitary adenoma, pituitary insufficiency, thyroid dysfunction, hypoparathyroidism, diabetes mellitus, hyponatriemia, hypogonadism, hyperhidrosis, osteoporosis), heart (cardiomyopathy, impulse generation or propagation abnormalities), eye (cataract, glaucoma, retinitis pigmentosa), ear (hypoacusis, tinnitus, vertigo), gastrointestinal tract (vomiting, pseudoobstruction, diarrhea, hepatopathy, liver cysts, pancreatitis), kidney (renal failure, renal cysts), bone marrow (anemia, leucopenia, thrombocytopenia, pancytopenia), bones (facial dysmorphism, hypertelorism), or dermis (lipoma, psoriasis, excema). Blood chemical investigations may show 
increased creatine-kinase, lactate or pyruvate (at rest or upon exercise). Serum and urine levels of amino acids may be elevated. Organic acids may be elevated in the urine. Lactate and pyruvate may be also elevated in the cerebro-spinal fluid (CSF). Nerve conduction studies may indicate neuropathy or neuronopathy and electromyography may show myogenic, neurogenic or non-specific changes. Neuroimaging may show a variety of abnormalities, including cortical, diffuse, or cerebellar atrophy, basal ganglia calcification, focal or diffuse demyelination, stroke-like lesions, laminar cortical necrosis, lacunas, cysts, or old ischemic lesions, Of paramount diagnostic importance is the detection of a biochemical defect of one of the $\mathrm{RC}$ complexes or the OXPHOS in any tissue or the detection of a known or new causative mtDNA or nDNA mutation.

\section{Mitochondrial disorders associated with ataxia}

\section{A. Disorders due to mutations in mtDNA genes}

Mitochondrial encephalomyopathy, lactacidosis, stroke-like episodes (MELAS)

Ataxia is not a common feature of MELAS syndrome, but has been reported in single patients. In a female with a MELAS phenotype since childhood, cognitive impairment and ataxia developed during the disease course (Table 3$)^{11}$. In this patient MELAS was due to the $7512 \mathrm{~T}>\mathrm{C}$ tRNASer mutation ${ }^{11}$. Ataxia has been also reported in a MELAS patient carrying the 3243A $>$ G mutation (Table 4) ${ }^{12}$.

\section{Myoclonic epilepsy and ragged red fibers (MERRF)}

Cerebellar ataxia is a common feature of MERRF syndrome. Nearly all MERRF patients present with cerebellar ataxia ${ }^{13}$. Cerebellar ataxia may be even the presenting manifestation in quite a number of patients (Table 3$)^{14}$. In addition, MERRF patients typically present with myoclonic epilepsy, and mitochondrial myopathy with ragged-red fibers ${ }^{15}$. More rarely patients develop dementia, parkinsonism, hypoacusis, optic atrophy, multiple lipomas, or foot deformities in the advanced stages $^{13,16,17}$. On cerebral magnetic resonance imaging (cMRI) atrophy of the cerebellar peduncles, the cerebellum, or the brainstem can be found ${ }^{14}$. Histopathological findings include degeneration of the dentate nuclei, globus pallidus, red nuclei, substantia nigra, inferior olivary nuclei, cerebellar cortex, or spinal cord. Particularly the posterior columns, the spinocerebellar tracts, or Clarc's columns are affected ${ }^{16}$. MERRF is most frequently due to point mutations in the tRNALys gene (Table 4).

\section{Leber's hereditary optic neuropathy (LHON)}

Only in single patients ataxia may be a supplementary feature in addition to optic atrophy (Table 3$)^{18,19}$. In such patients cMRI may reveal cerebellar atrophy ${ }^{19}$. LHON is due to homoplasmic mtDNA mutations affecting genes, which encode for subunits of RC complex I, III, IV, or V. Most frequently subunits of RC complex I are mutated in LHON. There are three primary LHON mutations, 3460A $>\mathrm{G}, 11778 \mathrm{~A}>\mathrm{G}$, and $14484 \mathrm{~T}>\mathrm{C}$, which account for $>95 \%$ of the cases (Table 4$)^{5,20}$. Only $50 \%$ of males and $10 \%$ of females, harboring a primary LHON-mutation,
Table 3: Syndromic MIDs associated with ataxia

\begin{tabular}{|c|c|}
\hline Syndrome & Type of ataxia \\
\hline \multicolumn{2}{|l|}{ mtDNA genes } \\
\hline \multicolumn{2}{|l|}{ Ataxia frequent } \\
\hline MERRF & $\mathrm{CA}$ \\
\hline NARP & SA \\
\hline MILS & $\mathrm{CA}$ \\
\hline KSS & $\mathrm{CA}$ \\
\hline \multicolumn{2}{|l|}{ Ataxia infrequent } \\
\hline MELAS & $\mathrm{CA}$ \\
\hline LHON & $\mathrm{CA}$ \\
\hline PS & $\mathrm{CA}$ \\
\hline MSL & $\mathrm{CA}$ \\
\hline MIDD & SA \\
\hline \multicolumn{2}{|l|}{ nDNA genes } \\
\hline \multicolumn{2}{|l|}{ Ataxia frequent } \\
\hline LS & $\mathrm{CA}$ \\
\hline SANDO & $\mathrm{CA}, \mathrm{SA}$ \\
\hline SCAE & CA, SA \\
\hline AHS & CA, SA \\
\hline XLSA/A & $\mathrm{CA}$ \\
\hline IOSCA & CA, SA \\
\hline MIRAS & CA, SA \\
\hline MEMSA & SA \\
\hline LBSL & $\mathrm{CA}$ \\
\hline CMT2A & SA \\
\hline FA & $\mathrm{CA}$ \\
\hline DCMA & $\mathrm{CA}$ \\
\hline \multicolumn{2}{|l|}{ Ataxia infrequent } \\
\hline AD-CPEO & $\mathrm{CA}$ \\
\hline AR-CPEO & CA, SA \\
\hline MNGIE & SA \\
\hline ADOAD & SA \\
\hline DIDMOAD & SA \\
\hline CoQ-deficiency & $\mathrm{CA}$ \\
\hline PDC-deficiency & $\mathrm{CA}$ \\
\hline
\end{tabular}

$\mathrm{CA}$ : cerebellar ataxia, $\mathrm{SA}$ : sensory ataxia

actually develop $\mathrm{LHON}^{20}$. The incomplete penetrance and the predominance of males suggest factors other than the primary LHON mutations (secondary LHON mutations, nDNA mutations) play a modifying role.

Neurogenic muscle weakness, ataxia, and retinitis pigmentosa (NARP)

The cardinal clinical features of NARP include neuropathy, cerebellar ataxia, and retinitis pigmentosa (Table 3$)^{21}$. Additional features include developmental delay, dementia, epilepsy, deafness, sensory neuropathy, or weakness ${ }^{22}$. Neuropathological findings comprise symmetrical lesions in the basal ganglia and brainstem, resembling those of $\mathrm{LS}^{23,24}$. The syndrome is most frequently caused by heteroplasmic point mutations in the ATP6 gene (Table 4$)^{21}$. The mutation load is particularly high in the cortex, putamen, thalamus, cerebellum, and brainstem ${ }^{24}$. Irrespective of the mutation load the ATP6 activity is reduced by about half of the normal value ${ }^{25}$. 
Table 4: Mutated genes responsible for syndromic and non-syndromic MIDs with ataxia

\begin{tabular}{|c|c|c|}
\hline Gene & Syndrome & Reference \\
\hline \multicolumn{3}{|l|}{ mtDNA } \\
\hline tRNASer & MELAS & [11] \\
\hline tRNALeu & MERRF & {$[14]$} \\
\hline \multirow[t]{3}{*}{ tRNALys } & MERRF & [95] \\
\hline & MSL & [40] \\
\hline & nsMID & {$[42]$} \\
\hline tRNAIle & nsMID & [41] \\
\hline tRNAGlu & nsMID & [43] \\
\hline ND1 & MILS & [96] \\
\hline ND4 & LHON & {$[19]$} \\
\hline ATP6 & MILS, NARP & {$[21.26,28]$} \\
\hline Del mtDNA & KSS & {$[33,34]$} \\
\hline Del mtDNA & PS & [31.32] \\
\hline \multicolumn{3}{|l|}{ nDNA } \\
\hline \multirow[t]{6}{*}{ POLG1 } & MEMSA, ANS & {$[6,52]$} \\
\hline & SANDO & {$[49,50]$} \\
\hline & MIRAS & {$[72,74]$} \\
\hline & AHS & {$[53,56]$} \\
\hline & AR-CPEO & [48] \\
\hline & SCAE & [52] \\
\hline \multirow[t]{5}{*}{ C10orf2/PEO1 } & $\mathrm{AD}-\mathrm{CPEO}$ & {$[46,47,57]$} \\
\hline & AHS & [57] \\
\hline & IOSCA & {$[57,74]$} \\
\hline & SANDO & [51] \\
\hline & SCAE & [52] \\
\hline \multirow[t]{3}{*}{ ANT1 } & AD-CPEO & {$[47,52]$} \\
\hline & nsMID & {$[52]$} \\
\hline & SCAE & [52] \\
\hline NDUFS1-8 & LS & [29] \\
\hline NDUFV1-2 & LS & [29] \\
\hline SURF1 & LS & {$[45]$} \\
\hline OPA1 & ADOAD & {$[67,68,69]$} \\
\hline DARS2 & LBSL & [76] \\
\hline$T P$ & MNGIE & [58] \\
\hline$A B C 7$ & XLSA/A & {$[64,66]$} \\
\hline WFS1, WFS2 & DIDMOAD & {$[79,80]$} \\
\hline PDHA1 & PDH deficiency/episodic ataxia at infancy & {$[84,85]$} \\
\hline$P D H B$ & PDH deficiency/episodic ataxia at infancy & [84] \\
\hline DNAJC19 & DCMA & [86] \\
\hline Frataxin & FA & {$[87,88]$} \\
\hline
\end{tabular}

nsMID: non-syndromic MID

and ataxia may be the only manifestation in mutation carriers ${ }^{28}$. Mito-chondrial genes most frequently mutated in MILS are the ND1-6, ATP6, COXIII, and tRNALys genes (Table 4) ${ }^{29}$. The mutation load correlates positively with the severity of the phenotype ${ }^{30}$.

\section{Pearson syndrome (PS)}

Pearson syndrome is an uncommon syndromic MID in infants, characterized by pancytopenia ${ }^{31}$. With disease progression, however, patients additionally develop muscle hypotonia, developmental delay, ataxia, tremor, hepatopathy, renal failure, or exocrine pancreatic dysfunction $^{31,32}$. Later on the phenotype may even turn into KSS or $\mathrm{LS}^{31}$. Muscle biopsy may show features of mitochondrial myopathy ${ }^{32}$. So far about 60 cases have been reported in the literature $^{31}$. As with KSS and CPEO, PS is due to single large-scale mtDNA deletions or duplications ${ }^{31,32}$.

\section{Kearns-Sayre syndrome (KSS)}

Typical features of KSS include CPEO, pigmentary retinopathy, and cardiac conduction disturbances ${ }^{33}$. Additional features include short stature, glaucoma, deafness, diabetes, primary amenorrhea, myopathy with ptosis and limb weakness, pyramidal signs, ataxia, and increased CSF protein content (Table 3) ) $^{33,34}$. In single patients KSS may be dominated by an ataxic syndrome $^{34}$. In accordance with the clinical findings, MRI often shows cerebellar or global atrophy. Additionally, there may be T2hyperintensities in the deep gray matter nuclei, the cerebellar white matter, or the subcortical white matter ${ }^{35}$. Kearns-Sayre syndrome is due to single large-scale mtDNA deletions or duplications ${ }^{35}$.

\section{Maternally inherited diabetes and deafness (MIDD)}

Maternally inherited diabetes and deafness syndrome presents clinically with diabetes and sensorineural hearing $\operatorname{loss}^{36}$. There are also families, which additionally present with

\section{Maternally inherited Leigh syndrome (MILS)}

Ataxia is present in nearly all patients with MILS. However, there is broad clinical and genetic heterogeneity. In a family carrying a mitochondrial ATP6 mutation, clinical manifestations ranged from late-onset MILS to NARP ${ }^{26}$. In another patient the 8993T $>$ C mutation caused MILS at early infancy, which disappeared over time, such that he was near normal at age 18 years ${ }^{21}$. Maternally inherited Leigh syndrome with predominant ataxia and neuropathy was diagnosed in a family carrying the 9185T >C mutation in the ATP6 gene with a heteroplasmy rate $>90 \%$ (Table 3) ${ }^{27}$. Other ATP6 mutations may also cause MILS features of MELAS syndrome ${ }^{37}$, including seizures, migraine, short stature, mental retardation, or stroke-like-episodes ${ }^{38}$. In single cases, ataxia may be a feature of the phenotype (Table 3$)^{39}$. Maternally inherited diabetes and deafness is due to mutations in the tRNALeu or tRNALys gene or due to large-scale tandem duplications or deletions/duplications (Table 4) 36,37. $^{36}$.

\section{Multiple symmetric lipomatosis (MSL)}

Multiple symmetric lipomatosis is a rare condition presenting with CPEO, hypoacusis, cerebellar ataxia, proximal myopathy, and polyneuropathy (Table 3$)^{40}$. Muscle biopsy may indicate mitochondrial myopathy. The genetic background is hetero- 
geneous, but a frequent mutation causing MSL is the $8344 \mathrm{~A}>\mathrm{G}$ transition in the $t R N A L y s$ gene (Table 4$)^{40}$.

\section{Non-syndromic MIDs}

In a family with the heteroplasmic tRNAIle gene mutation $4284 \mathrm{G}>\mathrm{A}$ the index patient's mother showed truncal ataxia, dysarthria, severe hearing loss, mental retardation, ptosis, ophthalmoparesis, distal myoclonus, and diabetes mellitus. RC complex I and IV activities were low in the muscle of the affected mother of the index patient ${ }^{41}$. Ataxia was also a feature in an Italian family with lipomas due to the mtDNA mutation $8363 \mathrm{G}>\mathrm{A}^{42}$. Ataxia was also a phenotypic manifestation of the $14680 \mathrm{C}>\mathrm{A}$ mtDNA mutation in a 14-year-old boy with exercise intolerance, weakness and lactic acidosis, who showed a mosaic pattern of succinate dehydrogenase staining on muscle biopsy ${ }^{43}$.

\section{B. MIDs due to $n D N A$ mutations}

\section{Leigh syndrome (LS)}

Leigh syndrome, also termed subacute, necrotizing encephalopathy, is the most frequent MID in childhood ${ }^{44}$. It is clinically characterized by a wide variety of abnormalities from severe neurological problems to almost absence of any abnormality. Most frequently the CNS is affected, including psychomotor retardation, seizures, nystagmus, ophthalmoparesis, optic atrophy, ataxia, dystonia, or respiratory failure (Table 3$)^{45}$. Some patients additionally present with polyneuropathy or myopathy, or non-neurological abnormalities, such as diabetes, short stature, hypertrichosis. cardiomyopathy, anemia, renal failure, vomiting, or diarrhea (Leigh-likesyndrome). On MRI, symmetric lesions, particularly in the basal ganglia, thalamus, or brainstem can be found ${ }^{29}$. Leigh syndrome is the MID with the widest genetic heterogeneity of all MIDs and may be due to mutations in the SURF1, NDUFS1-8, or NDUFV1-2 genes (Table 4) ${ }^{29}$.

\section{Autosomal dominant chronic external ophthalmoplegia (AD-} CPEO)

Autosomal dominant chronic external ophthalmoplegia may not only be restricted to the extra-ocular muscles but may also involve other systems, manifesting as proximal muscle weakness and wasting, hearing loss, or cerebellar ataxia (Table 3$)^{46}$. Multiple mtDNA deletions may be found in the skeletal muscle of these patients ${ }^{46}$. Responsible for the multiple mtDNA deletions are mutations in the ANT1, C10orf2 (twinkle), or POLGl genes ${ }^{47}$.

Autosomal recessive chronic external ophthalmoplegia (ARCPEO)

Rarely, ataxia may be also a feature of AR-CPEO, such as in a family with CPEO, polyneuropathy, sensorineural hearing loss, and affective disorder ${ }^{48}$. The syndrome was due to two heterozygous missense transitions in the POLGl gene ${ }^{48}$.

Sensory ataxia with neuropathy, dysarthria and ophthalmoparesis (SANDO)

AR Sensory ataxia with neuropathy, dysarthria and ophthalmoparesis syndrome was first reported in $1997^{49}$. Clinically, it is characterized by the triad of sensory or cerebellar ataxia, dysarthria, and ophthalmoparesis ${ }^{49}$. Additionally, there may be dysphagia, neuropathy or myopathy ${ }^{50}$. Genotypically, multiple mtDNA deletions due to POLG1 mutations ${ }^{49,50}$ or more rarely C10orf2 (twinkle) mutations are made responsible for the phenotype $^{51}$.

\section{Spino-cerebellar ataxia and epilepsy (SCAE)}

Juvenile-onset SCAE is characterised by a phenotype resembling that of a spinocerebellar ataxia with the difference that SCAE patients also develop seizures ${ }^{52}$. Most frequently SCAE is due to mutations in the POLG1, C10orf2 (twinkle), or ANT1 genes respectively ${ }^{52}$. A patient with CPEO and multiple mtDNA deletions additionally developed sensory and cerebellar ataxia peripheral neuropathy, parkinsonism, and depression. The complex phenotype in this patient resembled SCAE and was attributed to mutations in ANT1 and POLG1 genes with deleterious, secondary effects on mtDNA maintenance and integrity ${ }^{52}$.

\section{Alpers-Huttenlocher disease (AHS)}

Alpers-Huttenlocher disease starts in the first years of life with sudden onset intractable seizures, developmental delay, psychomotor regression, stroke-like episodes, muscle hypotonia, ataxia, cortical blindness, hepatic failure, fasting hypoglycemia, and death within a short time ${ }^{53,54}$. Muscle biopsy shows $C O X$ negative fibers ${ }^{55}$. Neuropathological investigations reveal cortical gliosis and subcortical loss of neurons, particularly in the thalamus ${ }^{55}$. Alpers-Huttenlocher disease is due to mutations in the POLG1 gene, secondarily causing mtDNA depletion ${ }^{56}$. The diagnosis is established by liver biopsy, muscle biopsy, or genetic testing. A phenotype similar to AHS, including muscle hypotonia, athetosis, sensory neuropathy, ataxia, hypoacusis, ophthalmoplegia, and intractable epilepsy was caused by C10orf2 (twinkle) mutations, resulting in hepatic mtDNA depletion ${ }^{57}$.

\section{Mitochondrial neuro-gastro-intestinal encephalomyopathy (MNGIE)}

Mitochondrial neuro-gastro-intestinal encephalomyopathy is an AR MID, characterized by nausea, vomiting, diarrhea ascites, gastrointestinal dysmotility, ophthalmoparesis, neuropathy, and mitochondrial myopathy ${ }^{58}$. Complementary features include ataxic gait, hearing loss, short stature, facial palsy, dysphonia, dysarthria, sweating, orthostatic hypotension, bladder dysfunction and hepatosplenomegaly ${ }^{58}$. Mitochondrial neurogastro-intestinal encephalomyopathy is due to mutations in the gene encoding for the thymidine-phosphorylase ${ }^{59,60}$, which plays an important role in the nucleoside metabolism by regulating the availability of thymidine for mitochondrial DNA synthesis ${ }^{61}$. The mutation secondarily causes mtDNA depletion or multiple mtDNA deletions. Thymidine-phosphorylase is also implicated in angiogenesis and cell trophism ${ }^{62}$.

\section{$X$-linked sideroblastic anemia with ataxia (XLSA/A)}

$\mathrm{X}$-linked sideroblastic anemia with ataxia is a rare syndromic MID, characterized by mild sideroblastic anemia with hypochromia and microcytosis and cerebellar ataxia (Table 3$)^{63-}$ 65. Cerebral imaging shows severe cerebellar atrophy. XLSA/A is 
due to mutations in the mitochondrial ATP-binding cassette transporter $A B C 7$ gene on chromosome Xq13 ${ }^{64,66}$.

\section{Autosomal dominant optic atrophy and deafness (ADOAD)}

Ataxia may be also a feature of ADOAD syndrome, which additionally presents with ataxia, axonal, sensorimotor neuropathy, CPEO, or mitochondrial myopathy (dominant optic atrophy "plus" syndrome ${ }^{67}$. Muscle biopsy may show mosaic COX-deficiency ${ }^{68}$. The syndrome is due to mutations in the OPAl gene, encoding for a dynamin-related GTPase, involved in mitochondrial fusion, cristae organization, and apoptosis ${ }^{67,69}$. Affected patients also harbor multiple mtDNA deletions, suggesting that $O P A 1$ is involved in mtDNA stability ${ }^{67}$. At onset OPA1 mutations may manifest exclusively as optic atrophy but during the disease course most patients develop ADOAD ${ }^{68}$.

\section{Infantile-onset spinocerebellar ataxia (IOSCA)}

AR Infantile-onset spinocerebellar ataxia is clinically characterized by cerebellar ataxia, epilepsy, athetosis, hypotonia, hypoacusis, CPEO, hypogonadism, and sensory neuropathy (Table 3$)^{70,71}$. Cerebral imaging may show progressive atrophy of the cerebellum, brainstem, or spinal cord ${ }^{71}$. Pathoanatomic studies confirm atrophy of the cerebellum, brainstem and, most severely, spinal cord ${ }^{70}$. IOSCA is caused by mutations in the ClOorf2/PEOl gene leading to an amino acid exchange in the mitochondrial helicase twinkle ${ }^{72}$. The mutation secondarily results in depletion of mtDNA in the brain and liver, which is why IOSCA is regarded as a depletion syndrome ${ }^{72}$. Biochemically, there is deficiency of RC complex I and $\mathrm{IV}^{72}$. In children there may be mtDNA depletion without demonstration of any mutation ${ }^{73}$.

\section{Mitochondrial autosomal recessive ataxia syndrome (MIRAS)}

Mitochondrial autosomal recessive ataxia syndrome is a common cause of AR juvenile- or adult-onset ataxia ${ }^{74}$. MIRAS is caused by homozygous or compound heterozygous mutations in the POLG1 gene resulting in multiple mtDNA deletions and to a lesser degree than in IOSCA also to mtDNA depletion ${ }^{72}$. Multiple mtDNA deletions are particularly present in the brain of these patients ${ }^{72}$. Biochemically, there is reduced activity of RC complex I and IV. In a study on 27 MIRAS patients they presented with ataxia, peripheral neuropathy, dysarthria, mild cognitive impairment, involuntary movements, psychiatric symptoms, and epileptic seizures ${ }^{75}$. Because of the high carrier frequency in Finland, the high number of patients in Norway, and an ancient European founder chromosome, MIRAS should be considered as a first-line differential diagnosis of progressive ataxia syndromes in Europe ${ }^{75}$.

Myoclonus epilepsy, mitochondrial myopathy, and sensory ataxia (MEMSA)

Myoclonus epilepsy, mitochondrial myopathy, and sensory ataxia patients present clinically with myoclonus epilepsy, mitochondrial myopathy, and sensory ataxia ${ }^{6}$. Myoclonus epilepsy, mitochondrial myopathy, and sensory ataxia is due to mutations in the POLG1 gene. In addition to MEMSA, POLG1 mutations cause myo-cerebro-hepatho spectrum (MCHS) disorders (SANDO, AHS), ataxia neuropathy spectrum (ANS) disorders (SCAE, MIRAS), AR-CPEO, and AD-CPEO ${ }^{6}$.

Leucencephalopathy with brainstem and spinal cord involvement, and lactacidosis (LBSL)

AR leucencephalopathy with brainstem and spinal cord involvement, and lactacidosis syndrome, a newly described entity, is clinically characterized by slowly progressive cerebellar ataxia, spasticity and dorsal column dysfunction ${ }^{76}$. Sometimes mild cognitive impairment may additionally develop. There is a highly characteristic constellation of abnormalities on $\mathrm{cMRI}^{76}$. The disorder is caused by mutations in the DARS 2 gene, which encodes for the mitochondrial aspartyl-tRNA synthetase ${ }^{76}$. Though activity of this mitochondrial protein is reduced in affected patients, function of the RC is intact ${ }^{76}$.

Diabetes insipidus, diabetes mellitus, optic atrophy, and deafness (DIDMOAD)

Diabetes insipidus, diabetes mellitus, optic atrophy, and deafness or Wolfram syndrome (WFS) is a rare AR neurodegenerative disorder with juvenile onset ${ }^{77}$. The phenotype is characterized by diabetes and optic atrophy. Other less frequent features comprise psychiatric abnormalities, ataxia, urinary tract atony, limited joint contractures, cardiovascular and gastrointestinal autonomic neuropathy, hyper-gonadotropic hypogonadism, cardiac malformations, or pituitary dysfunction ${ }^{77,78}$. Wolfram syndrome is due to mutations in the WFS1 gene on chromosome 4p16 or mutations in the WFS2 gene on chromosome $4 \mathrm{q} 22-24^{79,80}$. WSF1 and WSF2 mutations secondarily result in single or multiple mtDNA deletions ${ }^{81}$.

\section{Coenzyme-Q $($ CoQ $Q)$-deficiency}

Coenzyme-Q (CoQ)-deficiency is a genetically heterogenous disorder, presenting with four distinct phenotypes: a pure myopathic form, a severe infantile neurologic syndrome with nephritis, LS, or an ataxic variant ${ }^{82}$. Patients with the ataxic form present with epilepsy, weakness, cerebellar ataxia, cerebellar atrophy, migraine, myoglobinuria, or developmental delay ${ }^{83}$. The ataxic variant is the most common form characterized by cerebellar atrophy and cerebellar ataxia. Biochemically, there is deficiency of CoQ in muscle or fibroblasts. CoQ-deficiency responds well to CoQ-substitution ${ }^{82}$.

\section{Pyruvate-dehydrogenase complex (PDC)-deficiency}

The PDC converts pyruvate into acetyl-CoA within the mitochondrion. Mutations in the PDHAl gene may cause recurrent episodes of isolated ataxia in infancy ${ }^{84}$. Though patients gain full recovery between the episodes, they later develop severe encephalopathy and die in their twenties ${ }^{84}$. Ataxia in patients with PDC-deficiency due to mutations in the E1beta subunit $(P D H B)$ is usually less pronounced than in patients carrying $P D H A 1$ mutations ${ }^{85}$.

\section{Dilated cardiomyopathy with ataxia (DCMA)}

Dilated cardiomyopathy with ataxia was first described in a family from the Canadian Dariusleut Hutterite population ${ }^{86}$. Patients presented with early onset dilated cardiomyopathy with 
conduction defects, non-progressive cerebellar ataxia, testicular dysgenesis, growth failure, and 3-methylglutaconic aciduria ${ }^{86}$. The causative mutation was the point mutation IVS3-1 G $>\mathrm{C}$ in the DNAJC19 gene, encoding a DNAJ domain containing protein. The DNAJC19 protein is located inside mitochondria of cardiomyocytes, and shares sequence and organisational similarity with proteins from several species including the two yeast mitochondrial inner membrane proteins, Mdj2p and Tim14, suggesting that the phenotype of DCMA is the result of defective mitochondrial protein import ${ }^{86}$.

\section{Friedreich ataxia $(F A)$}

AR Friedreich ataxia is clinically characterized by cerebellar ataxia, spasticity, pyramidal signs, hypertrophic cardiomyopathy, and Friedreich's foot deformity (pes cavus) ${ }^{87}$. Additional features may include headache, dysarthria, dysphagia, vertigo, weakness, chorea, or anemia ${ }^{88,89}$. Scoliosis is found in two thirds of the cases and diabetes mellitus in one third ${ }^{88}$. Friedreich ataxia is the most common of the inherited ataxias. Friedreich ataxia is caused by a homozygous expansion of a GAA triplet repeat $(96 \%$ of the cases) or point mutations, located within intron 1 of the frataxin gene on chromosome $9 q 13^{87,88}$. Four percent of the patients are compound heterozygous, carrying a GAA expansion on one allele and a point mutation on the other ${ }^{88}$. Frataxin is a widely expressed mitochondrial protein, involved in RNA processing and intra-mitochondrial iron handling ${ }^{87}$ and directly involved in mitochondrial iron-binding and detoxification ${ }^{90}$. Frataxin mutations cause frataxin deficiency, which leads to iron accumulation and overload, increased sensitivity to oxidative stress, and deficient RC-activity ${ }^{87,90}$. Frataxin deficiency impairs mitochondrial functions either by a defect of iron/sulphur cluster construction or by the generation of free radicals.

\section{Non-syndromic MID}

Non-syndromic MIDs due to nDNA mutations are the most prevalent group of MIDs and genetically heterogenous. They comprise all those MIDs, which do not fit into the phenotype of any of the mitochondrial syndromes. As with syndromic MIDs the CNS is frequently involved and ataxia may be a dominant feature.

Among three patients carrying a mutation in the MPVI7 gene, resulting in hepatocerebral mtDNA depletion, two had severe, progressive liver disease, and the third patient a milder form but developed progressive ataxia ${ }^{91}$. In a patient simultaneously carrying a POLG1 and ANT1 mutation resulting in multiple mtDNA deletions, the phenotype included CPEO, sensory and cerebellar ataxia, neuropathy, parkinsonism and depression ${ }^{52}$. A POLG1 mutation also caused a phenotype with sensory ataxia, myoclonus, epilepsy, cognitive decline, nystagmus, dysarthria, and thalamic and cerebellar white matter lesions on MRI ${ }^{92}$. Another POLG1 mutation caused CPEO, polyneuropathy, ataxia, sensorineural hearing loss, and affective disorder ${ }^{48}$. In single cases the common ATP6 mutation 8993T >C may not only cause NARP or LS but may also manifest as adult onset ataxia and polyneuropathy ${ }^{93}$. Ataxia was also a phenotypic feature in a patient carrying a $t R N A G l u$ mutation. He additionally presented with exercise intolerance, weakness, and lactic acidosis ${ }^{43}$. Cerebellar ataxia was also a phenotypic feature in a 7-year-old male with CPEO, spasticity, and dystonia attributed to RC complex I deficiency due to a NDUFV1 mutation ${ }^{94}$. This mutation may be also associated with maternally inherited episodic ataxia ${ }^{93}$. In a study on five European MID families ataxia occurred in combination with various other CNS abnormalities. Cerebral MRI showed thalamic and cerebellar white matter lesions and autopsy neuronal loss in gray nuclei ${ }^{92}$. In eight patients the abnormalities could be attributed to $A R$ POLG1 mutations ${ }^{92}$.

\section{Discussion}

This review supports the notion that ataxia may be a more or less prominent feature of syndromic or non-syndromic MIDs either due to mutations in mtDNA or nDNA located genes. Mitochondrial disorders are associated with cerebellar as well as sensory ataxia and both may be present within the same patient or family. Mitochondrial disorders with ataxia are increasingly recognized and should be included in the differential diagnoses or classification of classical heredoataxias. This study also confirms that most MIDs do not nicely fit into one of the original acronyms but rather represent individual phenotypes, which more or less overlap with classical mitochondrial syndromes. Despite limited therapeutic options, neurologists should be aware of ataxia as a feature of MIDs, since it may guide them to the correct diagnosis, particularly if other neurological or nonneurological manifestations of a MID are present. Limitations of this study were that not all papers were accessible, that most studies did not clearly differentiate between cerebellar and sensory ataxia, and that most studies neither quantified the degree of ataxia nor described the course or outcome of the individual phenotypes.

\section{Conclusion}

This mini review shows that ataxia is a dominant feature of some MIDs with cerebral involvement. Cerebellar as well as sensory ataxia may occur in MID patients and may contribute to the disability in some of these patients. Ataxia is much more frequent in non-syndromic as compared to syndromic MIDs. As soon as ataxia is detected in patients with a phenotpye suggesting a MID, they should undergo a compreshensive neurological investigation, including cerebral imaging studies.

\section{LiST OF ABBREVIATIONS}

AD Autosomal dominant

ADOAD Autosomal dominant optic atrophy and deafness syndrome

AHS Alpers Huttenlocher syndrome

ANS Ataxia neuropathy spectrum disorders

AR Autosomal recessive

ATP Adenosine-tri-phosphate

ATP6 Subunit of complex V of the RC

CNS Central nervous system

CoQ Coenzyme Q

COX Cytochrome-c-oxidase

CPEO Chronic external ophthalmoplegia

CSF Cerebrospinal fluid

DARS2 Gene, which encodes mitochondrial aspartyl-tRNA synthetase

DIMOAD (WFS) Diabetes insipidus, diabetes mellitus, optic atrophy, deafness syndrome (Wolfram syndrome)

IOSCA Infantile-onset spinocerebellar atrophy 
KSS Kearns Sayre syndrome

LBSL Leucencephalopathy with brainstem and spinal cord involvement, and lactate elevation

LHON Leber's hereditary optic neuropathy

LS Leigh syndrome

MCHS Myo-cerebro-hepato spectrum disorders

MDS Mitochondrial depletion syndrome

MELAS Mitochondrial encephalomyopathy, lactacidosis, stroke-like episodes

MEMSA Myoclonus epilepsy, myopathy and sensory ataxia syndrome

MERRF Myoclonic epilepsy and ragged red fibers

MID Mitochondrial disorder

MIDs Mitochondrial disorders

MIDD Mitochondrial diabetes and deafness syndrome

MILS Maternally inherited Leigh syndrome

MIRAS Mitochondrial recessive ataxia syndrome

MNGIE Mitochondrial neuro-gastro-intestinal encephalomyopathy

MPV17 Mitochondrial inner membrane protein

cMRI Cerebral magnetic resonance imaging

MSL Multiple systemic lipomatosis

mtDNA Mitochondrial DNA

MTS (DDS) Mohr Tranebjaerg syndrome (deafness dystonia syndrome)

NARP Neurogenic muscle weakness, ataxia, and retinitis pigmentosa

ND1 Subunit of complex I of the RC

nDNA Nuclear DNA

OPA1 Optic atrophy 1 gene

OXPHOS Oxidative phosphorylation

PDC Pyruvate dehydrogenase complex

PDHA1 A1 subunit of the pyruvate dehydrogenase complex

PEO1 Progressive external ophthalmoplegia gene 1

PNS Peripheral nervous system

POLG Polymerase gamma

PS Pearson syndrome

PUS1 Pseudouridine synthase 1

RC Respiratory chain

rRNA Ribosomal ribonucleic acid

SANDO Sensory ataxic neuropathy, dysarthria, ophthalmoplegia syndrome

SCA Spino-cerebellar ataxia and epilepsy

SCAE Juvenile-onset spino-cerebellar ataxia and epilepsy

tRNA Transfer ribonucleic acid

XL X-linked

XLSA/A X-linked sideroblastic anemia with ataxia

\section{REFERENCES}

1. DiMauro S, Schon EA. Mitochondrial disorders in the nervous system. Annu Rev Neurosci. 2008;31:91-123.

2. Zeviani M, Di Donato S. Mitochondrial disorders. Brain. 2004;127: 2153-72.

3. Montirosso R, Brambilla D, Felisari G, Sclaunich F, Filipponi E, Pozzoli U, et al. Electrophysiological analysis of cognitive slowing in subjects with mitochondrial encephalomyopathy. J Neurol Sci. 2002;194:3-9.

4. Finsterer J. Overview on visceral manifestations of mitochondrial disorders. Neth J Med. 2006;64:61-71

5. Wong LJ, Naviaux RK, Brunetti-Pierri N, Zhang Q, Schmitt ES, Truong C, et al. Molecular and clinical genetics of mitochondrial diseases due to POLG mutations. Hum Mutat. 2008;29: E150-72.

6. Finsterer J. Ataxias with autosomal, X-chromosomal, or maternal inheritance. J Neurol Sci. 2009; In press 2009.

7. Orr HT, Zoghbi HY. Trinucleotide repeat disorders. Annu Rev Neurosci. 2007;30:575-621.
8. Schaefer AM, McFarland R, Blakely EL, He L, Whittaker RG, Taylor RW, et al. Prevalence of mitochondrial DNA disease in adults. Ann Neurol. 2008;63:35-9.

9. Chan SS, Longley MJ, Copeland WC. The common A467T mutation in the human mitochondrial DNA polymerase (POLG) compromises catalytic efficiency and interaction with the accessory subunit. J Biol Chem. 2005;280:31341-6.

10. Finsterer J, Harbo HF, Baets J, van Broeckhoven C, Di Donato S, Fontaine B, et al. EFNS guidelines for the molecular diagnosis of neurogenetic disorders (II). Mitochondrial disorders and dementia. Eur J Neurol. 2009; In press 2009.

11. Lindberg C, Moslemi AR, Oldfors A. MELAS syndrome in a patient with a point mutation in MTTS1. Acta Neurol Scand. 2008;117:128-32.

12. Petruzzella V, Zoccolella S, Amati A, Torraco A, Lamberti P, Carnicella F, et al. Cerebellar ataxia as atypical manifestation of the 3243A>G MELAS mutation. Clin Genet. 2004;65:64-5.

13. Teive HA, Munhoz RP, Muzzio JA, Scola RH, Kay CK, Raskin S, et al. Cerebellar ataxia, myoclonus, cervical lipomas, and MERRF syndrome. Case report. Mov Disord. 2008;23:1191-2.

14. Ito S, Shirai W, Asahina M, Hattori T. Clinical and brain MR imaging features focusing on the brain stem and cerebellum in patients with myoclonic epilepsy with ragged-red fibers due to mitochondrial A8344G mutation. Am J Neuroradiol. 2008;29: 392-5.

15. Orcesi S, Gorni K, Termine C, Uggetti C, Veggiotti P, Carrara F, et al. Bilateral putaminal necrosis associated with the mitochondrial DNA A8344G myoclonus epilepsy with ragged red fibers (MERRF) mutation: an infantile case. J Child Neurol. 2006;21:79-82.

16. Fukuhara N. Fukuhara disease. Brain Nerve. 2008;60:53-8.

17. Horvath R, Kley RA, Lochmüller H, Vorgerd M. Parkinson syndrome, neuropathy, and myopathy caused by the mutation A8344G (MERRF) in tRNALys. Neurology. 2007;68:56-8.

18. Funakawa I, Kato H, Terao A, Ichihashi K, Kawashima S, Hayashi $\mathrm{T}$, et al. Cerebellar ataxia in patients with Leber's hereditary optic neuropathy. J Neurol. 1995;242:75-7.

19. Murakami T, Mita S, Tokunaga M, Maeda H, Ueyama H, Kumamoto T, et al. Hereditary cerebellar ataxia with Leber's hereditary optic neuropathy mitochondrial DNA 11778 mutation. J Neurol Sci. 1996;142:111-3.

20. Man PY, Turnbull DM, Chinnery PF. Leber hereditary optic neuropathy. J Med Genet. 2002;39:162-9.

21. Debray FG, Lambert M, Lortie A, Vanasse M, Mitchell GA. Longterm outcome of Leigh syndrome caused by the NARP-T8993C mtDNA mutation. Am J Med Genet. 2007;143A:2046-51.

22. Tsao CY, Mendell JR, Bartholomew D. High mitochondrial DNA T8993G mutation (<90\%) without typical features of Leigh's and NARP syndromes. J Child Neurol. 2001;16:533-5.

23. Mitani M, Jinnai K, Takahashi K, Koide R, Tsuji S. A case of NARP (neurogenic muscle weakness, ataxia, and retinitis pigmentosa) with a T-to-C point mutation at nt 8993 of mitochondrial DNA. Clin Neurol. 2000;40:600-4.

24. Rojo A, Campos Y, Sánchez JM, Bonaventura I, Aguilar M, García A, et al. NARP-MILS syndrome caused by $8993 \quad \mathrm{~T}>\mathrm{G}$ mitochondrial DNA mutation: a clinical, genetic and neuropathological study. Acta Neuropathol. 2006;111:610-16.

25. Uziel G, Moroni I, Lamantea E, Fratta GM, Ciceri E, Carrara F, et al. Mitochondrial disease associated with the T8993G mutation of the mitochondrial ATPase 6 gene: a clinical, biochemical, and molecular study in six families. J Neurol Neurosurg Psychiatry. 1997:63:16-22

26. Childs AM, Hutchin T, Pysden K, Highet L, Bamford J, Livingston $\mathrm{J}$, et al. Variable phenotype including Leigh syndrome with a 9185T>C mutation in the MTATP6 gene. Neuropediatrics. 2007; 38:313-6.

27. Castagna AE, Addis J, McInnes RR, Clarke JT, Ashby P, Blaser S, et al. Late onset Leigh syndrome and ataxia due to a $\mathrm{T}$ to $\mathrm{C}$ mutation at bp 9,185 of mitochondrial DNA. Am J Med Genet. 2007;143A:808-16.

28. Campos Y, Martin MA, Rubio JC, Solana LG, García-Benayas C, Terradas JL, et al. Leigh syndrome associated with the T9176C mutation in the ATPase6 gene of mitochondrial DNA. Neurology. 1997;49:595-7. 
29. Finsterer J. Leigh and Leigh-like syndrome in children and adults. Pediat Neurol. 2008;39:223-35.

30. Santorelli FM, Shanske S, Macaya A, DeVivo DC, DiMauro S. The mutation at nt 8993 of mitochondrial DNA is a common cause of Leigh's syndrome. Ann Neurol. 1993;34:827-34.

31. Lee HF, Lee HJ, Chi CS, Tsai CR, Chang TK, Wang CJ. The neurological evolution of Pearson syndrome: case report and literature review. Eur J Paediatr Neurol. 2007;11:208-14.

32. McShane MA, Hammans SR, Sweeney M, Holt IJ, Beattie TJ, Brett EM, et al. Pearson syndrome and mitochondrial encephalomyopathy in a patient with a deletion of mtDNA. Am J Hum Genet. 1991;48:39-42.

33. Riera AR, Kaiser E, Levine P, Schapachnik E, Dubner S, Ferreira C, et al. Kearns-Sayre syndrome: electro-vectorcardiographic evolution for left septal fascicular block of the his bundle. J Electrocardiol. 2008;41:675-8.

34. Zoccolella S, Torraco A, Amati A, Lamberti P, Serlenga L, Papa S, et al. Unusual clinical presentation of a patient carrying a novel single $1.8 \mathrm{~kb}$ deletion of mitochondrial DNA. Funct Neurol. 2006;21:39-41.

35. Hourani RG, Barada WM, Al-Kutoubi AM, Hourani MH. Atypical MRI findings in Kearns-Sayre syndrome: T2 radial stripes. Neuropediatrics. 2006;37:110-13.

36. Van den Ouweland JM, Lemkes HH, Ruitenbeek W, Sandkuijl LA, de Vijlder MF, Struyvenberg PA, et al. Mutation in mitochondrial tRNA(Leu)(UUR) gene in a large pedigree with maternally transmitted type II diabetes mellitus and deafness. Nat Genet. 1992;1:368-71.

37. Van den Ouweland JM, Lemkes HH, Gerbitz KD, Maassen JA, et al. Maternally inherited diabetes and deafness (MIDD): a distinct subtype of diabetes associated with a mitochondrial tRNA(Leu)(UUR) gene point mutation. Muscle Nerve. 1995:3:S124-30

38. Chen YN, Liou CW, Huang CC, Lin TK, Wei YH. Maternally inherited diabetes and deafness (MIDD) syndrome: a clinical and molecular genetic study of a Taiwanese family. Chang Gung Med J. 2004;27:66-73.

39. Kobayashi Z, Tsunemi T, Miake H, Tanaka S, Watabiki S, Morokuma Y. A mother and a child with maternally inherited diabetes and deafness (MIDD) showing atrophy of the cerebrum, cerebellum and brainstem on magnetic resonance imaging (MRI). Intern Med. 2005;44:328-31.

40. Naumann M, Kiefer R, Toyka KV, Sommer C, Seibel P, Reichmann H. Mitochondrial dysfunction with myoclonus epilepsy and ragged-red fibers point mutation in nerve, muscle, and adipose tissue of a patient with multiple symmetric lipomatosis. Muscle Nerve. 1997;20:833-9.

41. Corona P, Lamantea E, Greco M, Carrara F, Agostino A, Guidetti D, et al. Novel heteroplasmic mtDNA mutation in a family with heterogeneous clinical presentations. Ann Neurol. 2002;51: $118-22$.

42. Casali C, Fabrizi GM, Santorelli FM, Colazza G, Villanova M, Dotti MT, et al. Mitochondrial G8363A mutation presenting as cerebellar ataxia and lipomas in an Italian family. Neurology. 1999;52:1103-4

43. Pancrudo J, Shanske S, Bonilla E, Daras M, Akman HO, Krishna S, et al. Mitochondrial encephalomyopathy due to a novel mutation in the tRNAGlu of mitochondrial DNA. J Child Neurol. 2007; 22:858-62.

44. Zeviani M, Bertagnolio B, Uziel G. Neurological presentations of mitochondrial diseases. J Inherit Metab Dis. 1996;19:504-20.

45. Salviati L, Freehauf C, Sacconi S, DiMauro S, Thoma J, Tsai AC. Novel SURF1 mutation in a child with subacute encephalopathy and without the radiological features of Leigh Syndrome. Am J Med Genet. 2004;128A:195-8.

46. Kawai H, Akaike M, Yokoi K, Nishida Y, Kunishige M, Mine H, et al. Mitochondrial encephalomyopathy with autosomal dominant inheritance: a clinical and genetic entity of mitochondrial diseases. Muscle Nerve. 1995;18:753-60.

47. Spinazzola A, Viscomi C, Fernandez-Vizarra E, Carrara F, D'Adamo P, Calvo S, et al. MPV17 encodes an inner mitochondrial membrane protein and is mutated in infantile hepatic mitochondrial DNA depletion. Nat Genet. 2006;38: $570-5$.
48. Mancuso M, Filosto M, Bellan M, Liguori R, Montagna P, Baruzzi A, et al. POLG mutations causing ophthalmoplegia, sensorimotor polyneuropathy, ataxia, and deafness. Neurology. 2004; 62:316-8

49. Gago MF, Rosas MJ, Guimarães J, Ferreira M, Vilarinho L, Castro L, et al. SANDO: two novel mutations in POLG1 gene. Neuromuscul Disord. 2006;16:507-9.

50. Milone M, Brunetti-Pierri N, Tang LY, Kumar N, Mezei MM, Josephs K, et al. Sensory ataxic neuropathy with ophthalmoparesis caused by POLG mutations. Neuromuscul Disord. 2008;18:626-32.

51. Hudson G, Deschauer M, Busse K, Zierz S, Chinnery PF. Sensory ataxic neuropathy due to a novel $\mathrm{C} 10 \mathrm{Orf} 2$ mutation with probable germline mosaicism. Neurology. 2005;64:371-3.

52. Galassi G, Lamantea E, Invernizzi F, Tavani F, Pisano I, Ferrero I, et al. Additive effects of POLG1 and ANT1 mutations in a complex encephalomyopathy. Neuromuscul Disord. 2008;18: 465-70.

53. Gordon N. Alpers syndrome: progressive neuronal degeneration of children with liver disease. Dev Med Child Neurol. 2006;48: 1001-3.

54. Naviaux RK, Nyhan WL, Barshop BA, Poulton J, Markusic D, Karpinski NC, et al. Mitochondrial DNA polymerase gamma deficiency and mtDNA depletion in a child with Alpers' syndrome. Ann Neurol. 1999;45:54-8.

55. Kollberg G, Moslemi AR, Darin N, Nennesmo I, Bjarnadottir I, Uvebrant $\mathrm{P}$, et al. POLG1 mutations associated with progressive encephalopathy in childhood. J Neuropathol Exp Neurol. 2006; 65:758-68.

56. Davidzon G, Mancuso M, Ferraris S, Quinzii C, Hirano M, Peters HL, et al. POLG mutations and Alpers syndrome. Ann Neurol. 2005;57:921-3.

57. Hakonen AH, Isohanni P, Paetau A, Herva R, Suomalainen A, Lönnqvist T. Recessive Twinkle mutations in early onset encephalopathy with mtDNA depletion. Brain. 2007;130: 3032-40.

58. Debouverie M, Wagner M, Ducrocq X, Grignon Y, Mousson B, Weber M. MNGIE syndrome in 2 siblings. Rev Neurol (Paris). 1997; 153:547-53.

59. DiMauro S, Schon EA. Mitochondrial respiratory-chain diseases. N Engl J Med. 2003;348:2656-68.

60. Nishigaki Y, Marti R, Hirano M. ND5 is a hot-spot for multiple atypical mitochondrial DNA deletions in mitochondrial neurogastrointestinal encephalomyopathy. Hum Mol Genet. 2004; 13:91-101

61. Marti R, Spinazzola A, Tadesse S, Nishino I, Nishigaki Y, Hirano M. Definitive diagnosis of mitochondrial neurogastrointestinal encephalomyopathy by biochemical assays. Clin Chem. 2004; $50: 120-4$

62. Gillis L, Kaye E. Diagnosis and management of mitochondrial diseases. Pediatr Clin N Am. 2002;49:203-19.

63. Allikmets R, Raskind WH, Hutchinson A, Schueck ND, Dean M, Koeller DM. Mutation of a putative mitochondrial iron transporter gene $(\mathrm{ABC} 7)$ in X-linked sideroblastic anemia and ataxia (XLSA/A). Hum Mol Genet. 1999;8:743-9.

64. Pondarre C, Campagna DR, Antiochos B, Sikorski L, Mulhern H, Fleming MD. Abcb7, the gene responsible for X-linked sideroblastic anemia with ataxia, is essential for hematopoiesis. Blood. 2007;109:3567-9.

65. Hellier KD, Hatchwell E, Duncombe AS, Kew J, Hammans SR. Xlinked sideroblastic anaemia with ataxia: another mitochondrial disease? J Neurol Neurosurg Psychiatry. 2001;70:65-9.

66. Maguire A, Hellier K, Hammans S, May A. X-linked cerebellar ataxia and sideroblastic anaemia associated with a missense mutation in the $\mathrm{ABC} 7$ gene predicting V411L. Br J Haematol. 2001;115:910-17.

67. Amati-Bonneau P, Valentino ML, Reynier P, Gallardo ME, Bornstein $\mathrm{B}$, Boissière $\mathrm{A}$, et al. OPA1 mutations induce mitochondrial DNA instability and optic atrophy 'plus' phenotypes. Brain. 2008;131:338-51. 
68. Hudson G, Amati-Bonneau P, Blakely EL, Stewart JD, He L, Schaefer AM, et al. Mutation of OPA1 causes dominant optic atrophy with external ophthalmoplegia, ataxia, deafness and multiple mitochondrial DNA deletions: a novel disorder of mtDNA maintenance. Brain. 2008;131:329-37.

69. Liguori M, La Russa A, Manna I, Andreoli V, Caracciolo M, Spadafora $\mathrm{P}$, et al0. A phenotypic variation of dominant optic atrophy and deafness (ADOAD) due to a novel OPA1 mutation. J Neurol. 2008;255:127-9.

70. Lönnqvist T, Paetau A, Nikali K, von Boguslawski K, Pihko H. Infantile onset spinocerebellar ataxia with sensory neuropathy (IOSCA): neuropathological features. J Neurol Sci. 1998;161: $57-65$.

71. Nikali K, Suomalainen A, Saharinen J, Kuokkanen M, Spelbrink JN, Lönnqvist T, et al. Infantile onset spinocerebellar ataxia is caused by recessive mutations in mitochondrial proteins Twinkle and Twinky. Hum Mol Genet. 2005;14:2981-90.

72. Hakonen AH, Goffart S, Marjavaara S, Paetau A, Cooper H, Mattila $\mathrm{K}$, et al. Infantile-onset spinocerebellar ataxia and mitochondrial recessive ataxia syndrome are associated with neuronal complex I defect and mtDNA depletion. Hum Mol Genet. 2008;17: 3822-35.

73. Goffart S, Cooper HM, Tyynismaa H, Wanrooij S, Suomalainen A, Spelbrink JN. Twinkle mutations associated with autosomal dominant progressive external ophthalmoplegia lead to impaired helicase function and in vivo mtDNA replication stalling. Hum Mol Genet. 2009;18:328-40.

74. Rantamäki M, Luoma P, Virta JJ, Rinne JO, Paetau A, Suomalainen A, et al. Do carriers of POLG mutation W748S have disease manifestations? Clin Genet. 2007;72:532-7.

75. Hakonen AH, Heiskanen S, Juvonen V, Lappalainen I, Luoma PT, Rantamaki M, et al. Mitochondrial DNA polymerase W748S mutation: a common cause of autosomal recessive ataxia with ancient European origin. Am J Hum Genet. 2005;77:430-41.

76. Scheper GC, van der Klok T, van Andel RJ, van Berkel CG, Sissler M, Smet J, et al. Mitochondrial aspartyl-tRNA synthetase deficiency causes leukoencephalopathy with brain stem and spinal cord involvement and lactate elevation. Nat Genet. 2007; 39:534-9.

77. Medlej R, Wasson J, Baz P, Azar S, Salti I, Loiselet J, et al. Diabetes mellitus and optic atrophy: a study of Wolfram syndrome in the Lebanese population. J Clin Endocrinol Metab. 2004;89: 1656-61.

78. Barrett TG, Bundey SE, Macleod AF. Neurodegeneration and diabetes: UK nationwide study of Wolfram (DIDMOAD) syndrome. Lancet. 1995;346:1458-63.

79. Ajlouni K, Jarrah N, El-Khateeb M, El-Zaheri M, El Shanti H, Lidral A, et al. Wolfram syndrome: identification of a phenotypic and genotypic variant from Jordan. Am J Med Genet. 2002; 115:61-5.

80. Cryns K, Sivakumaran TA, Van den Ouweland JM, Pennings RJ, Cremers CW, Flothmann K, et al. Mutational spectrum of the WFS1 gene in Wolfram syndrome, nonsyndromic hearing impairment, diabetes mellitus, and psychiatric disease. Hum Mutat. 2003;22:275-87.

81. Barrientos A, Casademont J, Saiz A, Cardellach F, Volpini V, Solans A, et al. Autosomal recessive Wolfram syndrome associated with an 8.5-kb mtDNA single deletion. Am J Hum Genet. 1996;58: 963-70.
82. Montero R, Pineda M, Aracil A, Vilaseca MA, Briones P, SánchezAlcázar JA, et al. Clinical, biochemical and molecular aspects of cerebellar ataxia and Coenzyme Q10 deficiency. Cerebellum. 2007;6:118-22

83. Leshinsky-Silver E, Levine A, Nissenkorn A, Barash V, Perach M, Buzhaker E, et al. Neonatal liver failure and Leigh syndrome possibly due to CoQ-responsive OXPHOS deficiency. Mol Genet Metab. 2003;79:288-93.

84. Debray FG, Lambert M, Gagne R, Maranda B, Laframboise R, MacKay N, et al. Pyruvate dehydrogenase deficiency presenting as intermittent isolated acute ataxia. Neuropediatrics. 2008;39: 20-3.

85. Okajima K, Korotchkina LG, Prasad C, Rupar T, Phillips JA 3rd, Ficicioglu $\mathrm{C}$, et al. Mutations of the Elbeta subunit gene (PDHB) in four families with pyruvate dehydrogenase deficiency. Mol Genet Metab. 2008;93:371-80.

86. Davey KM, Parboosingh JS, McLeod DR, Chan A, Casey R, Ferreira P, et al. Mutation of DNAJC19, a human homologue of yeast inner mitochondrial membrane co-chaperones, causes DCMA syndrome, a novel autosomal recessive Barth syndromelike condition. J Med Genet. 2006;43:385-93.

87. Lodi R, Rajagopalan B, Bradley JL, Taylor DJ, Crilley JG, Hart PE, et al. Mitochondrial dysfunction in Friedreich's ataxia: from pathogenesis to treatment perspectives. Free Radic Res. 2002;36: 461-6.

88. Spacey SD, Szczygielski BI, Young SP, Hukin J, Selby K, Snutch TP. Malaysian siblings with Friedreich ataxia and chorea: a novel deletion in the frataxin gene. Can J Neurol Sci. 2004;31:383-6.

89. Samad FU, Engel E, Hartmann RC. Hypoplastic anemia, Friedreich's ataxia and chromosomal breakage: case report and review of similar disorders. South Med J. 1973;66:135-40.

90. Campanella A, Isaya G, O'Neill HA, Santambrogio P, Cozzi A, Arosio $\mathrm{P}$, et al. The expression of human mitochondrial ferritin rescues respiratory function in frataxin-deficient yeast. Hum Mol Genet. 2004;13:2279-88.

91. Parini R, Furlan F, Notarangelo L, Spinazzola A, Uziel G, Strisciuglio $\mathrm{P}$, et al. Glucose metabolism and diet-based prevention of liver dysfunction in MPV17 mutant patients. J Hepatol. 2009;50:215-21.

92. Van Goethem G, Luoma P, Rantamaki M, Al Memar A, Kaakkola $\mathrm{S}$, Hackman $\mathrm{P}$, et al. POLG mutations in neurodegenerative disorders with ataxia but no muscle involvement. Neurology. 2004;63:1251-7.

93. Craig K, Elliott HR, Keers SM, Lambert C, Pyle A, Graves TD, et al. Episodic ataxia and hemiplegia caused by the 8993T- $>$ C mitochondrial DNA mutation. J Med Genet. 2007;44:797-9.

94. Laugel V, This-Bernd V, Cormier-Daire V, Speeg-Schatz C, de Saint-Martin A, Fischbach M. Early-onset ophthalmoplegia in Leigh-like syndrome due to NDUFV1 mutations. Pediatr Neurol. 2007;36:54-7.

95. Oldfors A, Holme E, Tulinius M, Larsson NG. Tissue distribution and disease manifestations of the tRNA(Lys) A-->G(8344) mitochondrial DNA mutation in a case of myoclonus epilepsy and ragged red fibres. Acta Neuropathol. 1995;90:328-33.

96. Moslemi AR, Darin N, Tulinius M, Oldfors A, Holme E. Two new mutations in the MTATP6 gene associated with Leigh syndrome. Neuropediatrics. 2005;36:314-18. 